\title{
Sciences
}

Vol. 06, No. 04, pp. 107-119, December 2013

\section{DESIGN AND SIMULATION OF SELF TUNING CONTROLLER FOR DC SERVO MOTOR}

\author{
Mustafa A. Khamis \\ Assistant Lecturer, Electrical Department - Baquba Technical Institute, Iraq. \\ E-mail: Mustafa_electronic@yahoo.com \\ (Received: 25/7/2011; Accepted:29 /10/2013)
}

\begin{abstract}
This paper presents an adaptive controller which improves the tracking performance between the plant and the desired response to obtain model following (the plant response completely follow the desired response). The DC servo motor is used (with fixed and variable load) as the plant response for the adaptive controller and the type of the controller that designed in this paper is indirect self-tuning controller STC with the parameters estimation. The parameters estimation is obtained by using the Least Square Estimation method and the model following is achieved by pole placement design method. Matlab program is used to design and simulation the controller and the simulation results show that the tracking error is reduced until becomes zero. At this point the DC servomotor response is closed to the desired response by the proposed controller as applied to the dc servomotor, also when the gain or the load of the DC servo motor is changed the output response of the STC is closed to the desired response after some time due to the estimation process, and the best value of the forgetting factor is less than one.
\end{abstract}

\section{1- INTRODUCTION}

An adaptive controller is a controller that can modify its behavior in response to the variations in the dynamics of the process and the character of the disturbances. The controller parameters may be adjusted by some mechanism. There is a wide variety of mechanisms for adjustment, among which system identification of the control object, and some performance measure of the system such as output variance. The aim of an adaptive controller is to automatically provide a competitive controller in situations where the dynamics of the control object may be varying ${ }^{(1)}$. The block diagram of an adaptive system is shown in fig. (1). 
There has been growing awareness over the last decade that adaptive can produce an improved performance in real applications, mainly as a result of considerable advances in the understanding of adaptive control theory as well as in computer technology. From design engineering point of view, a suitable adaptive controller should be able to accommodate the following requirements ${ }^{(2)}$ : -

1. Large applicability-the plant to be controlled may exhibit non - minimum phase and/ or unstable behavior, and unknown possibly variable time delay.

2. The control law should provide an acceptable stability margin

3. Simple performance specification.

4. Robust parameter estimator the adaptive law should accommodate external disturbances, parameter variations and un modeled dynamics.

5. Implementation simplicity - the resulting control system should be implemented with a reasonable hardware / software complexity.

\section{2 - SELF TUNING CONTROLLER}

A digital self-tuning controller is a controller that during each sample interval performs three major steps shown in Fig. (2). ${ }^{(3)}$

- Estimates the parameters of the discrete plant model.

- Calculates the controller parameters using the estimated plant model parameters.

- Calculates and implements the new control signal.

\section{3 - ESTIMATION ALGORITHMS}

It is important to estimate the process parameters on-line in adaptive control. For an adaptive control system, the adaptive mechanism is based on identifying the system first. A self-tuning regulator includes a recursive parameter estimator. Simply speaking the process parameters estimation is a part of the system identification. In a broader sense, system identification is the selection of model structure, experiment design, and parameter estimation. ${ }^{(4)}$.

\section{4- PROCESS MODEL:}

It is assumed that the process is described by the single input, single output (SISO) system.

$$
A\left(z^{-1}\right) y(k)=B\left(z^{-1}\right)\left(u\left(k-d_{0}\right)+v\left(k-d_{0}\right)\right)
$$


Where

$$
\begin{array}{lr}
A\left(z^{-1}\right)=1+a_{1} z^{-1}+\ldots \ldots .+a_{n} z^{-n} & 2 \\
B\left(z^{-1}\right)=b_{0}+b_{1} z^{-1}+\ldots \ldots . . b_{m} z^{-m} & 3
\end{array}
$$

With $m=n-d_{o}$. In eq. (1) $y$ is the output, $u$ is the input of the system, and $v$ is a disturbance. The disturbance can enter the system in many ways. Here it has been assumed that $\mathrm{v}$ enters at the process input.

\section{5-LEAST SQUARE ESTIMATION ALGORITHM}

The least square method is commonly used in system identification. Its principle is that the unknown parameters of a mathematical model should be chosen by minimizing the sum of the square of the difference between the actually observed and the analytically predicted output values In adaptive control system the observation is obtained sequentially in real time. Recursive estimation algorithm is desirable. It saves the possible weighting that measure the degree of precision. The least-square criterion is quadratic, so an analytic solution to the least square problem exists as computation time by using the results obtained at time $(\mathrm{t}-1)$ to get the estimates at time $(\mathrm{t}$ ). Hence, the recursive least-square (RLS) estimation method is used in this section. The process model eq.(1) can be rewritten as: [5]

$$
y(k)=-a_{1} y(k-1)-a_{2} y(k-2)-\cdots-a_{n} y(k-n)+b_{o} u\left(k-d_{o}\right)+\cdots+b_{m} u\left(k-d_{o}-m\right) \quad 4
$$

The model is linear in the parameters and can be written in the vector form as:

$$
\begin{aligned}
& y(k)=\varphi^{T}(k) \theta_{e} \\
& \theta_{e}=\left[b_{o}, b_{1}, \ldots, b_{m}, a_{1}, a_{2}, \ldots, a_{n}\right] \\
& \varphi(k)=\left[u\left(k-d_{o}\right), \ldots, u\left(k-d_{o}-m\right),-y(k-n)\right]^{T} \\
& \hat{\theta}_{e}=\hat{\theta}_{e}(k-1)+K(k)\left[y(k)-\varphi^{T}(k) \hat{\theta}_{e}(k-1)\right] \\
& K(k)=P(k-1) \varphi(k)\left(I+\varphi^{T}(k) P(k-1) \varphi(k)\right)^{-1} \\
& \mathrm{p}(\mathrm{k})=\left(\mathrm{I}-\mathrm{K}(\mathrm{k}) \varphi^{\mathrm{T}}(\mathrm{k})\right) \mathrm{P}(\mathrm{k}-1)
\end{aligned}
$$

The RLS algorithm above can be interpreted intuitively. The estimate $\grave{\theta}(k)$ is obtained by adding a weighted prediction error term $y(k)-\varphi^{T}(k) \grave{\theta}(k-1)$ to the previous estimate $\grave{\theta}(k-1)$. The term $\varphi^{T}(k) \dot{\theta}(k-1)$ can be viewed as the value of $\mathrm{y}$ at time $\mathrm{k}$ predicted by the model eq. (5) with the previous estimates $\dot{\theta}(k-1)$. RLS estimation algorithm usually has several modified versions suitable for specific applications. For instance, RLS with exponential forgetting algorithm is designed to estimate the system with slow time varying parameters, in 
model eq. (5). In this pragmatic approach, we simply introduce a time varying weighting of the data. The latest data is weighted by 1 , but the data that is $n$ time units old is weighted by $\lambda^{n}(\lambda$ is called the forgetting factor, $0<\lambda<1$ ). Its basic idea is to assign the time-varying information with different importance. This algorithm is listed as follows: ${ }^{(5)}$

$$
\begin{array}{cc}
\hat{\theta}_{e}=\hat{\theta}_{e}(k-1)+k(k)\left\lfloor y(k)-\varphi^{T}(k) \hat{\theta}_{e}(k-1)\right\rfloor & 11 \\
K(k)=P(k-1) \varphi(k)\left(I \lambda+\varphi^{T}(k) P(k-1) \varphi(k)\right)^{-1} & 12 \\
P(k)=\frac{P(k-1)}{\lambda}-P(k-1) \varphi(k)\left[I+\varphi^{T}(k) P(k-1) \varphi(k)\right]^{-1} \times \frac{\varphi^{T}(k) P(k-1)}{\lambda} & 13
\end{array}
$$

\section{6- POLE PLACEMENT DESIGN}

Pole placement design is a standard controller design, useful for SISO systems it is commonly used as the design methodology in indirect adaptive controllers. In this application it is often used with polynomial input-output representation,to correspond to the estimated transfer function of the unknown system, often obtained from RLS parameter estimation. Consider the discrete-time system representation.

$$
y(k)=\frac{B}{A} u(k)
$$

Consider also the general controller:

$$
\mathrm{Ru}=\mathrm{Tu}_{\mathrm{c}}-\mathrm{Gy}
$$

Where R, G, and T are polynomials. This control law represents a negative feedback with the transfer operator $-G / R$ and a feed forward with the transfer operator T/R. Elimination of $u$ between eqs. (14) and (15) gives the following equation for the closed loop system:

$$
(\mathrm{AR}+\mathrm{BG}) \mathrm{y}=\mathrm{BTu}_{\mathrm{c}}
$$

The process zeros, given by $(\mathrm{B}=0)$, will also be closed loop zeros unless they are canceled by corresponding closed loop poles. Since unstable or poorly damped zeros cannot be canceled, the polynomial $\mathrm{B}$ is factored as:

$$
B=B^{+} B^{-}
$$

Where $\mathrm{B}^{+}$contains ining factor can be interpreted as observer dynamic $\mathrm{A}_{\mathrm{o}}$. Hence the observer dynamics should be faster than the desired closed loop response determined by $A_{m}$ ${ }^{(6)}$.The three types of factors of the characteristic polynomial: canceled process zeros given by $\mathrm{B}^{+}$, desired model poles giving by $\mathrm{A}_{\mathrm{m}}$, and observer poles given by the observer polynomial $\mathrm{A}_{\mathrm{o}}$. Therefore: 


$$
A R+B G=B^{+} A_{0} A_{m}
$$

This is called the Diophantine equation. It follow from this equation that $\mathrm{B}^{+}$divides

$$
\mathrm{R}=\mathrm{B}^{+} \mathrm{R}_{1}
$$

Dividing eq. (18) by $\mathrm{B}^{+}$gives:

$$
A R_{1}+B^{-} G=A_{0} A_{m} \quad 20
$$

The requirement that the relation between the command signal $\mathrm{u}_{\mathrm{c}}$ and the response output $\mathrm{y}$ in the eq. (16) should be equal to the desired closed loop response. The specifications must also be such that $\mathrm{B}^{-}$divided $\mathrm{B}_{\mathrm{m}}$; otherwise there is no solution to the design problem. Hence:

$$
\begin{gathered}
B_{m}=B^{-} B_{m}^{\prime} \\
T=A_{o} B_{m}^{\prime}
\end{gathered}
$$

The solution of the problem must give conditions to guarantee that there exist solutions to eq.(20) which gives a proper (continuous-time) or causal (discrete time) control law ${ }^{(5)}$

$$
\begin{array}{ll}
\operatorname{deg} A_{\mathrm{m}}-\operatorname{deg} \mathrm{B}_{\mathrm{m}} \geq \operatorname{deg} \mathrm{A}-\operatorname{deg} \mathrm{B} & 23 \\
\operatorname{deg} A_{o} \geq 2 \operatorname{deg} A-\operatorname{deg} A_{m}-\operatorname{deg} B^{+}-1 & 24
\end{array}
$$

\section{7- MINIMUM-DEGREE POLE PLACEMENT (MDPP)}

Data: polynomials A and B

Specification: polynomials $\mathrm{A}_{\mathrm{m}}, \mathrm{B}_{\mathrm{m}}$ and $\mathrm{A}_{\mathrm{o}}$

\section{Compatibility conditions:}

$$
\begin{aligned}
& \operatorname{deg} A_{m}=\operatorname{deg} A \\
& \operatorname{deg} B_{m}=\operatorname{deg} \mathbf{B} \\
& \operatorname{deg} A_{\mathrm{o}}=\operatorname{deg} \mathrm{A}-\operatorname{deg} \mathrm{B}^{+}-1 \\
& B_{m}=B^{-} B_{m}^{\prime}
\end{aligned}
$$

Step-1: Decompose B as $B=B^{+} B^{-}$

Step-2: Solve the Diophantine equation below to get R' and $\mathrm{S}$ with

$$
\begin{aligned}
& \operatorname{deg} \mathrm{G}<\operatorname{deg} \mathrm{R} \\
& A R^{\prime}+B^{-} G=A_{o} A_{m}
\end{aligned}
$$


Step-3: From control signal $T=A_{0} \bar{B}_{m}$ and $R=B^{+} R^{\prime}$. Compute the control signal from the control signal

$R u=T u_{c}-G y$

\section{8- DESIGN AND SIMULATION OF ADAPTIVE CONTROLLER FOR DC SERVOMOTOR:}

The design of adaptive controller for dc motor is used to achieve a dynamic performance in the time domain which is defined in terms of parameters of the system response to the step input. The most frequently used parameters are the settling time $\left(\mathrm{t}_{\mathrm{s}}\right)$, the rise time $\left(t_{r}\right)$, and the percent over shoot $\left(M_{p}\right)$. The transfer function of the dc servomotor is ${ }^{(7)}$

$$
\frac{\omega(\mathrm{s})}{\mathrm{v}(\mathrm{s})}=\frac{\mathrm{k}}{\left(\mathrm{L}_{\mathrm{a}} \mathrm{s}+\mathrm{R}_{\mathrm{a}}\right)(\mathrm{Js}+\mathrm{b})+\mathrm{k}^{2}} \quad 25
$$

Where the voltage is the input and the rotational velocity $\omega$ is the output, $k=k_{t}$ (armature constant) $=\mathrm{k}_{\mathrm{e}}$ (motor constant), $\mathrm{L}_{\mathrm{a}}$ is the armature inductance, $\mathrm{R}_{\mathrm{a}}$ is armature resistance, $\mathrm{J}$ is the moment of inertia of rotor, and $\mathrm{b}$ is the mechanical system damping ratio. The velocity transfer function equation (25) needs Dc motor parameters to design the adaptive controller system. Therefore the parameters below are chosen from the reference ${ }^{(7)}$ for a permanent magnet Dc motor as an example to be applied in this work.

\begin{tabular}{|c|c|c|c|c|}
\hline $\mathrm{R}_{\mathrm{a}}$ & $\mathrm{J}$ & $\mathrm{K}$ & $\mathrm{L}_{\mathrm{a}}$ & $\mathrm{b}$ \\
\hline $0.75 \Omega$ & $0.015 \mathrm{~kg} \cdot \mathrm{m}^{2}$ & $\begin{array}{c}0.0175 \\
N m / A m p\end{array}$ & $0.65 \mathrm{H}$ & $0.085 \mathrm{~N} \cdot \mathrm{sec}$ \\
\hline
\end{tabular}

Substituting these parameters by eq.(25) results in:

$$
\frac{\omega(\mathrm{s})}{\mathrm{v}(\mathrm{s})}=\frac{1.79}{\mathrm{~s}^{2}+5.6 \mathrm{~s}+6.5}
$$

The output step response of this transfer function with the desired response $\left(\omega_{n}=5\right.$ and $\xi=0.7$ ) is shown in fig.(3). The obtained control signal from the adaptive controller are changed to pulses with variable width by using the pulse width modulator. Then applied into the driver circuit in order to apply different average voltages across the motor. We convert this transfer function to discrete with the sampling time $h=0.5$ yields: 


$$
\frac{y(z)}{u(z)}=\frac{0.0931 z+0.03761}{z^{2}-0.5781 z+0.06081}
$$

The desired transfer function response $\left(\mathrm{w}_{\mathrm{n}}=5\right.$ and $\left.\xi=0.7\right)$ is given as

$\frac{y_{m}(s)}{u_{c}(s)}=\frac{25}{s^{2}+7 s+25}$

Converting into discrete time with the sampling time $h=0.5$ yields:

$$
\frac{y_{m}(z)}{u_{c}(z)}=\frac{0.8706 z+0.2336}{z^{2}+0.074 z+0.0302}
$$

The observer polynomial is given in the form of according to eq. (24):

$$
A_{0}(z)=z+a_{0}
$$

The value of $a_{0}$ which is less than to one (take 0.1 ) and the observer polynomial becomes

$$
A_{0}(z)=z+0.1
$$

To find the controller polynomials we apply the Diophantine eq. (20) by comparing the coefficients. The $\mathrm{T}(\mathrm{z})$ polynomials may then be calculated using the eq. (22):

$$
\begin{gathered}
T(z)=\beta A_{0}(z) \\
\beta=\frac{1+a_{m 1}+a_{m 2}}{b_{1}+b_{2}}=\frac{1+0.074+0.0302}{0.07117+0.02707}=11.39 \\
T(z)=11.39 z+1.139
\end{gathered}
$$

The pulses input to the Dc motor instead of step input because we want to show how the model following is achieved. Fig. (4) and (5) show the output and the control signal of the process when an indirect self-tuning controller is used with least square estimation. Fig. (6) shows that the estimates of the process parameters rapidly converge to the true model parameters. Fig. (7) show the effect of the forgetting factor to the output process and the best value is $(\lambda<1)$. The output response of the STC for changing the plant gain into two times more (3.58 instead of 1.79) is shown in fig. (8). Fig. (9) shows the output response when changed the moment of inertia of the load to 0.02 . we notes that the process output follow the desired response until close to it and the tracking error is become zero.

\section{9-CONCLUSION}

Following conclusions may be drawn from the simulation results:

1- The plant response followed the reference model until closed to it after some time due to the estimation process. Fig. (4) shows this fact.

2- The better values of the forgetting factor are $(\lambda<1)$. Fig. (7) shows the effect of increasing it to 1.5 . 
3- When changed the gain of the Dc servomotor or changed the moment of inertia; the tracking error is reduced until becomes zero and the STC response is closed to the desired response. Fig. (8) and (9) show this fact.

\section{REFERENCES}

1. Brad Schofield "Subspace Based Identification for Adaptive Control", M. Sc. Thesis. Department of Automatic Control, Lund Jnstitute of Technology. June, 2003.

2. M. M' Saad I. D. Landau, M. Dugue and M.Samaan, "Example Applications of the Partial State Model Reference Adaptive Design Technique”, int. J. of Adaptive Control and Signal Processing vol.3, 1989.

3. Fatima Tahri, Ali Tahri, Ahmed Allali and Samir Flazi, "The Digital Self-Tuning Control of Step a Down DC-DC Converter" Department of Electrotechnics,University of Sciences and Technology of Oran, Algeria. Acta Polytechnica Hungarica. Vol. 9, No. 6, 2012.

4. Andrew C. Clegg "Self tuning position and force control of a Haydraulic manipulator", Thesis submitted for the degree of Doctor of philosophy, Heriot-Watt university. November 2000.

5. Karl John Astrom, Bjorn Wittenmark “Adaptive Control”, Addison, Wesley publishing Company 1995.

6. Astrom, K. J., and B. Wittenmark, 1972 “On Self Tuning Regulator” Utomatica 9: 185199.

7. Kasim Karam "Dc motor speed controller Employing FPGA", M.Sc. Thesis, electrical and electronic department, University of Technology, October 2004. 


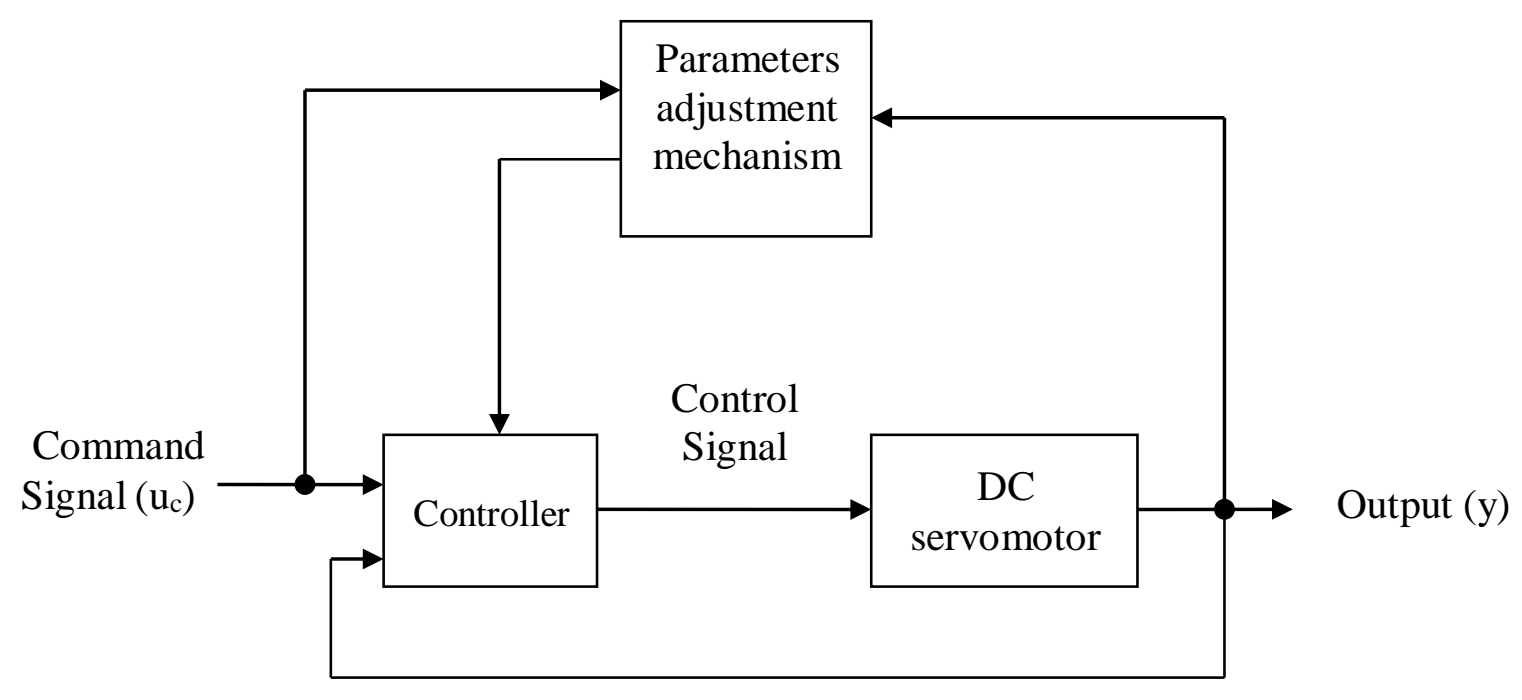

Fig. (1): Adaptive control system.

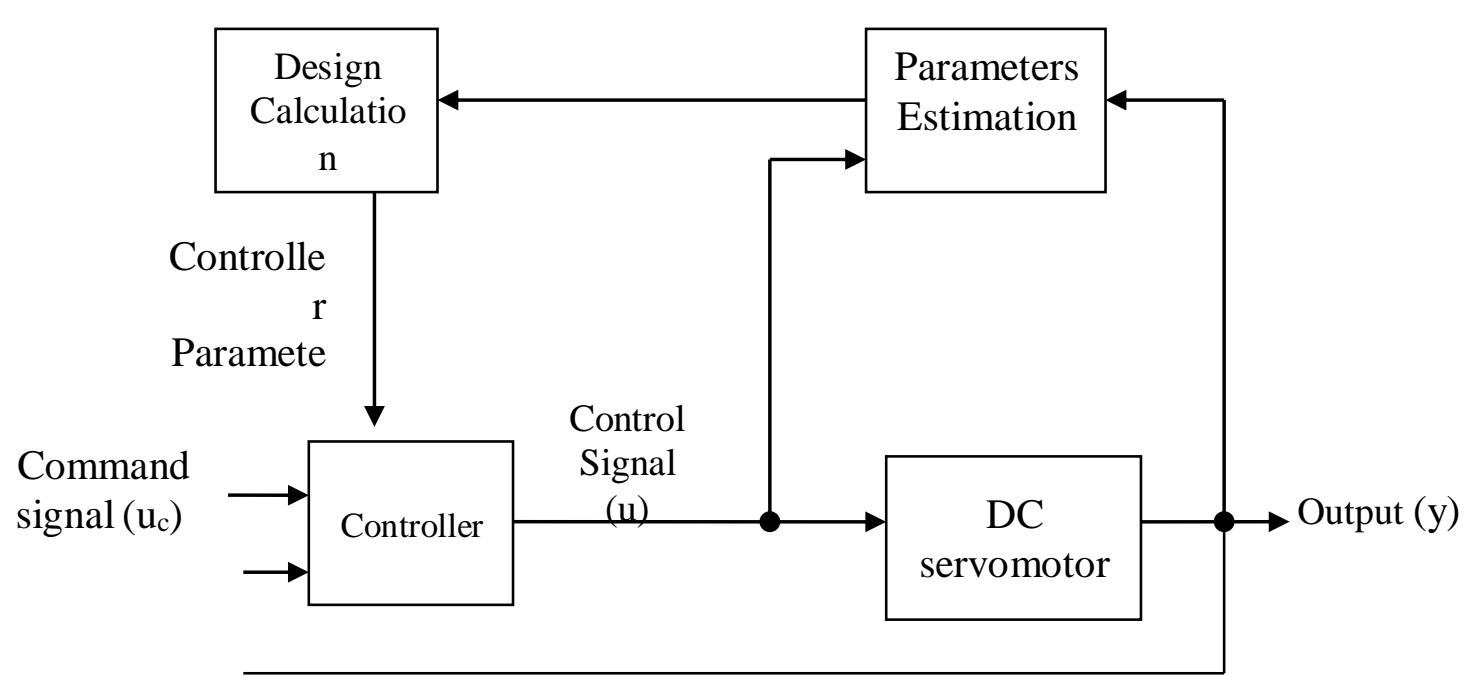

Fig.(2): Indirect self-tuning controller.

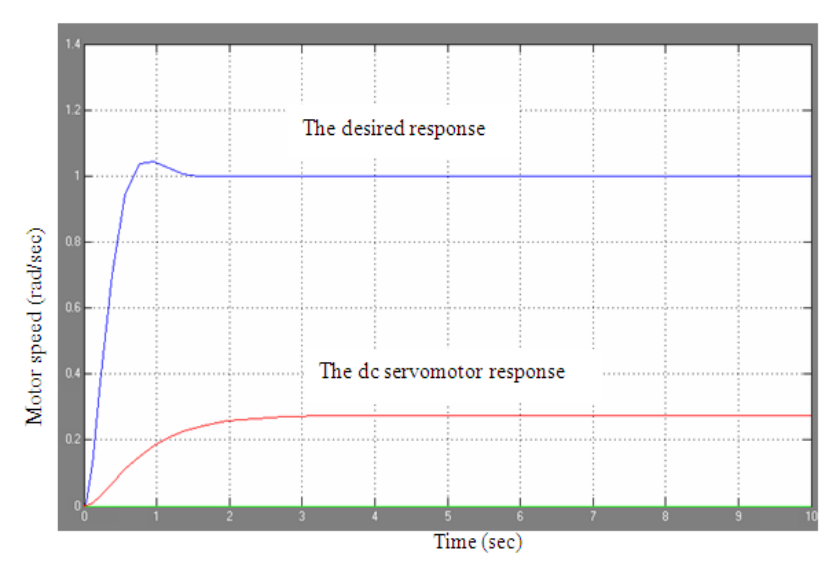

Fig.(3): Motor and desired response. 


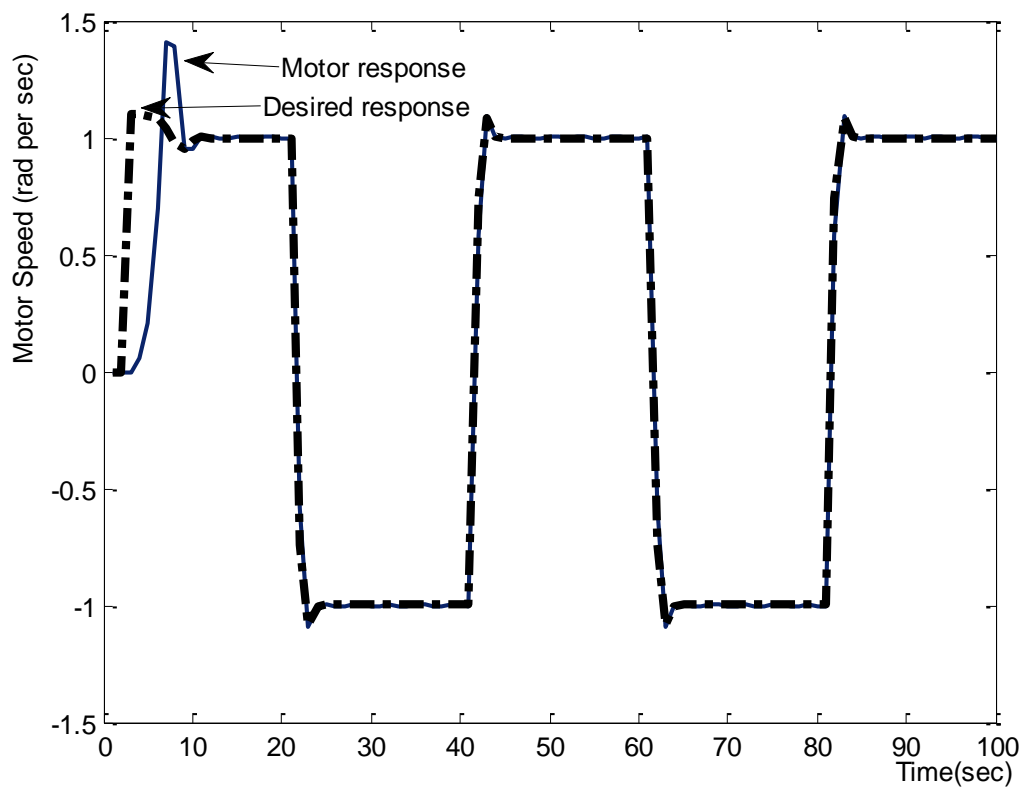

Fig. (4): The output process at $(\lambda=0.1)$.

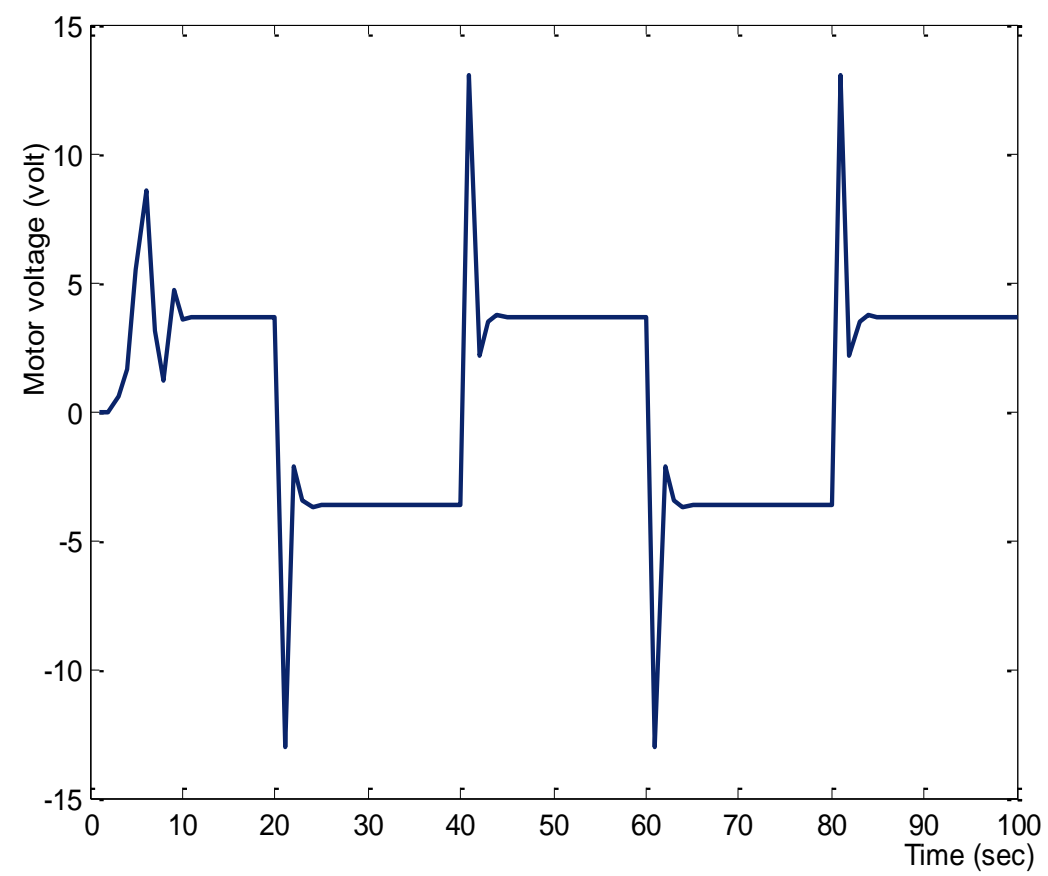

Fig. (5): The control signal. 

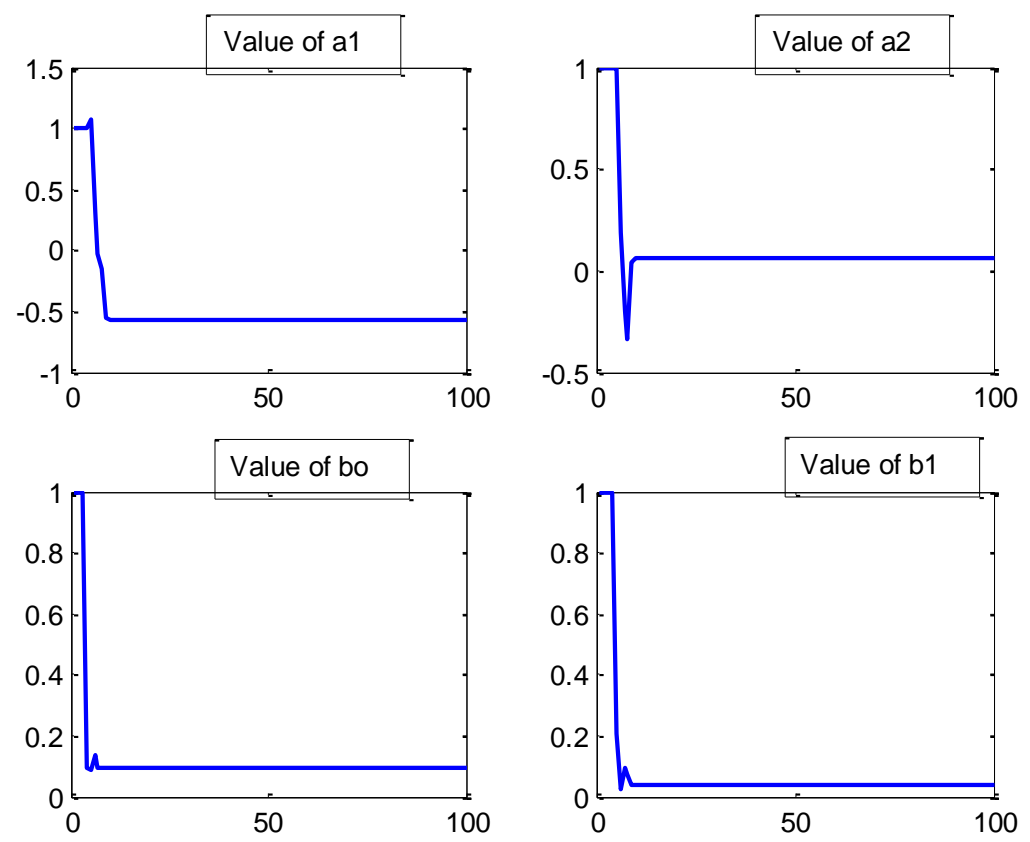

Fig. (6): The process parameters estimation.

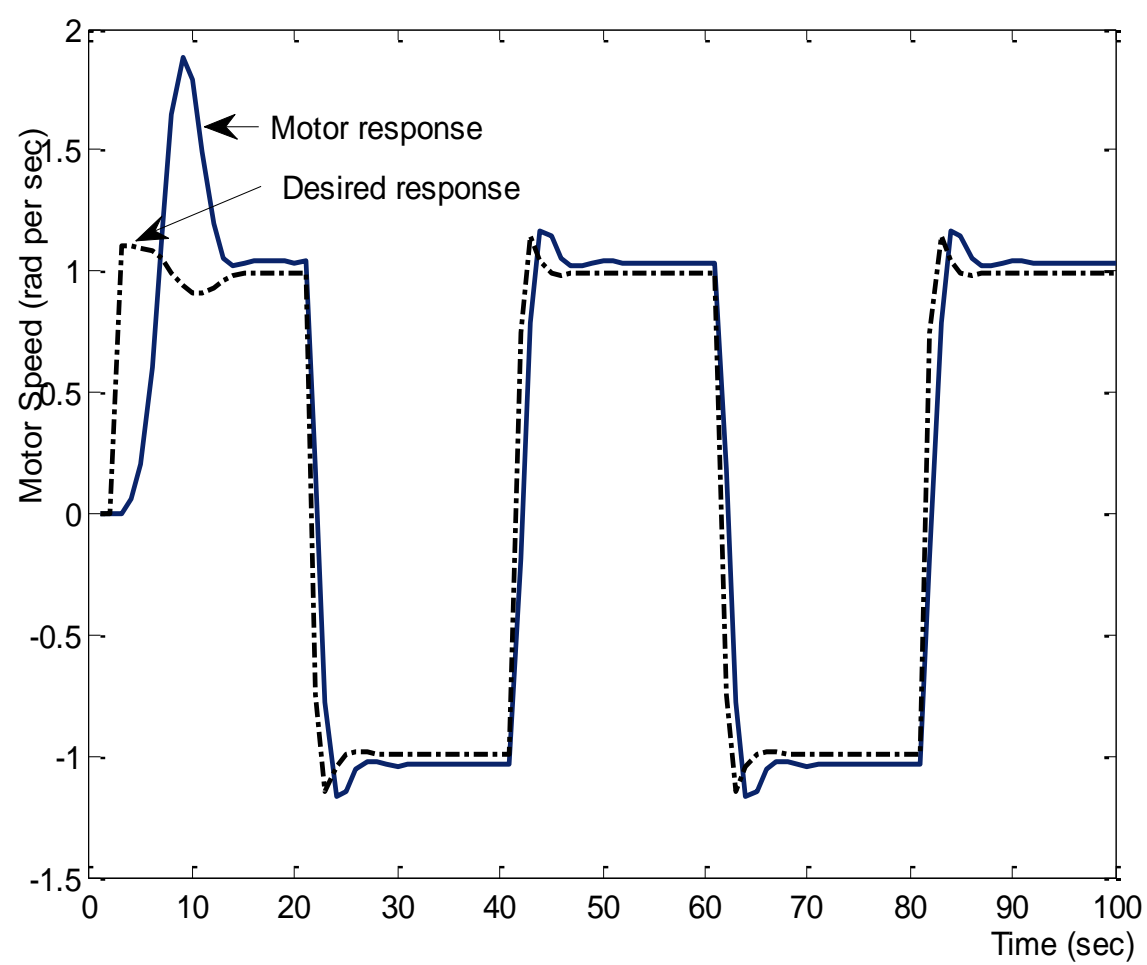

Fig. (7): The output process at $(\lambda=1.5)$. 


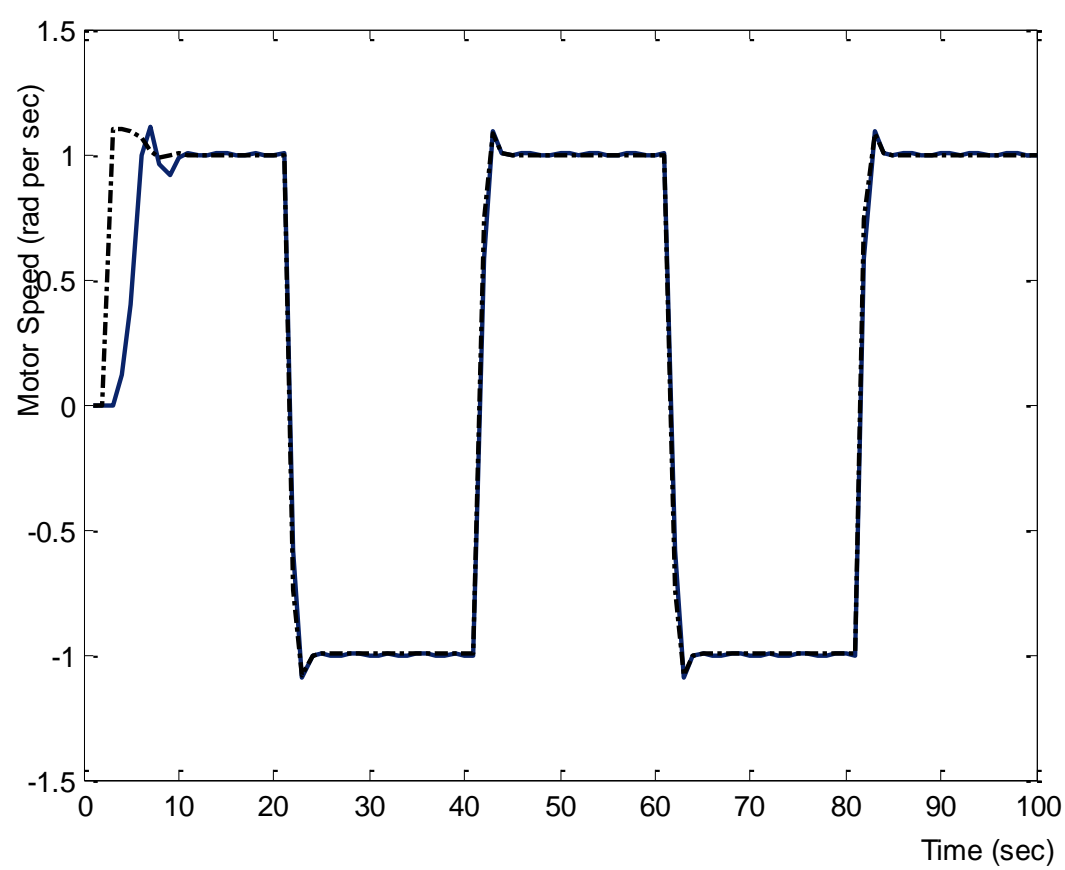

Fig. (8): The output process when change the motor constant to two times at $(\lambda=0.1)$.

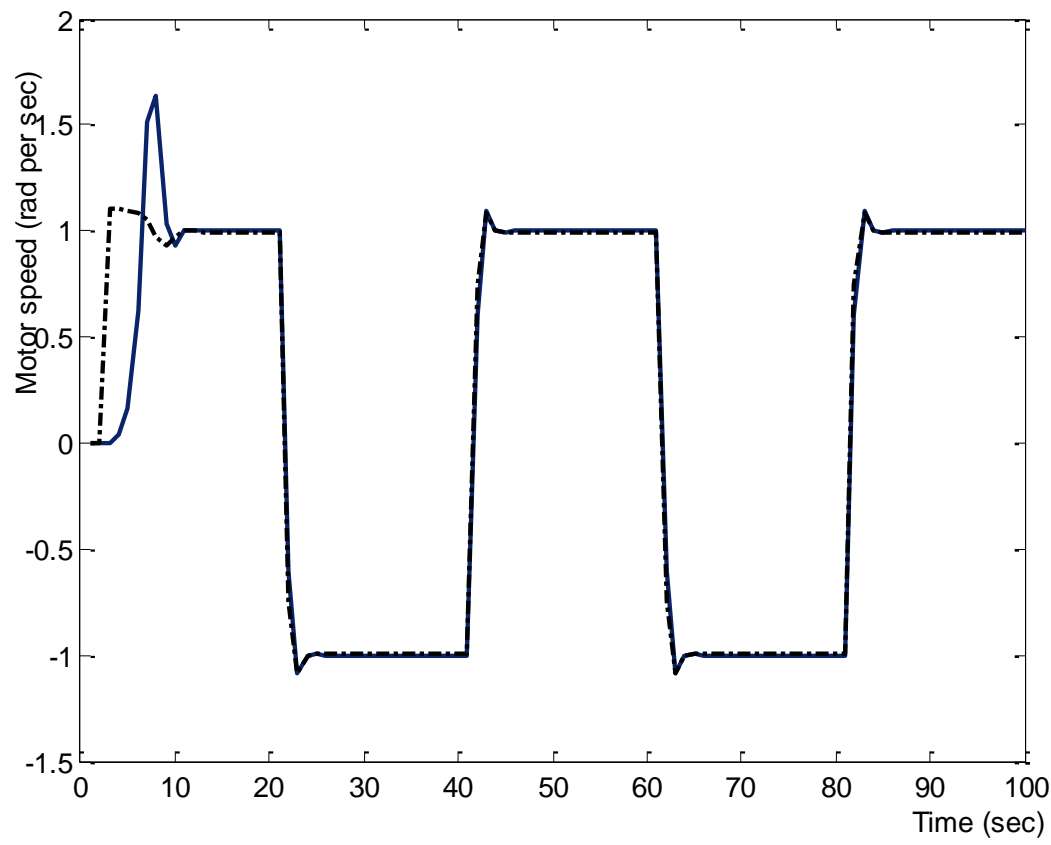

Fig. (9): The output process when change the moment of inertia of the motor to $0.02 \mathrm{~kg} \cdot \mathrm{m}^{2}$ at $(\lambda=0.1)$. 
تصميم ومحاكاة مسيطر الاستدارة الذاتي لمحرك التيار المستمر

\author{
مصطقى احمد خميس \\ مدرس مساعد \\ قسم الكهرباء/ المعهد التقني/ بعقوبة/ ديالى/ العراق
}

هذا العمل قدم المسيطر المتكيف الذي حسن في انجاز التتابع ما بين استجابة النظام والاستجابة المطلوبة

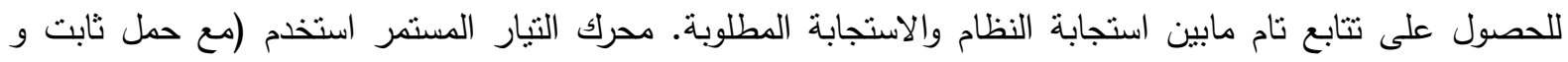
متغير) من اجل المسيطر المتكيف، وان نوع المسيطر المستخدم في هذا العمل هو مسيطر الاستخارة الذاتي الغير مباشر

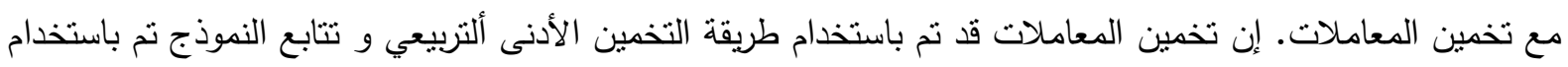

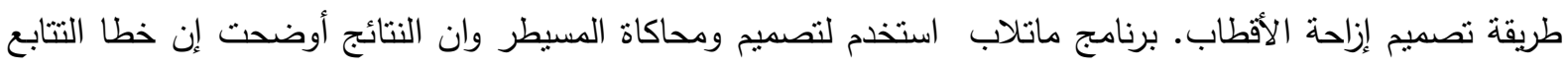
يقل حتى يصبح صفر في هذه النقطة تغلق استجابة المحرك إلى الاستجابة المطلوبة كذلك عند تغيير في ربح أو في

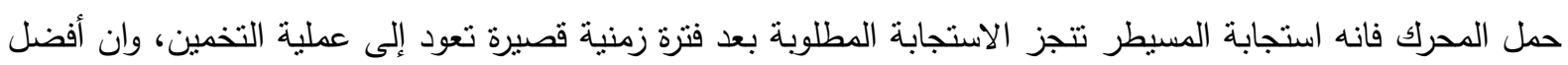
قيمة لعامل النسيان هي اقل من الواحد. 